\title{
Intralobar pulmonary sequestration with aspergillus infection and elevated serum CA19-9 and CA242: a case report
}

\author{
Li Ge ${ }^{1,2}$, Shan Wang ${ }^{2}$, Hongrui Liu ${ }^{2}$, Xiaohua Shi ${ }^{2}$, Juhong Shi ${ }^{3}$, Ruie Feng ${ }^{2}$ \\ ${ }^{1}$ Department of Pathology, Weifang People's Hospital, Weifang, China; ${ }^{2}$ Department of Pathology, Peking Union Medical College Hospital, Chinese \\ Academy of Medical Sciences \& Peking Union Medical College, Beijing, China; ${ }^{3}$ Department of Respiratory, Peking Union Medical College \\ Hospital, Chinese Academy of Medical Sciences \& Peking Union Medical College, Beijing, China \\ Correspondence to: Juhong Shi. Department of Respiratory, Peking Union Medical College Hospital, Chinese Academy of Medical Sciences \& Peking \\ Union Medical College, Beijing, China. Email: juhong_shi@hotmail.com; Ruie Feng. Department of Pathology, Peking Union Medical College \\ Hospital, Chinese Academy of Medical Sciences \& Peking Union Medical College, Beijing, China. Email: fengruie1@163.com.
}

\begin{abstract}
Pulmonary sequestration is a rare congenital dysplasia, and intralobar pulmonary sequestration was caused by aspergillus infection are more uncommon. The significant increase of serum CA19-9 and CA242 often indicates malignant tumors of the pancreas, biliary tract and gastrointestinal tract, but it is different in this case we reported. We present a case of a 36-year-old woman with intralobar pulmonary sequestration with aspergillus infection and elevated serum tumor markers CA19-9 and CA242. The patient had a right lung occupying lesion on the chest CT and sulfur particles are formed in the lesioned bronchial lumen. According to the results of the imaging and pathological, and serum CA19-9 and CA242 increased significantly, it was initially suspected to be a malignant tumor, so the right lobectomy and lymph node dissection were performed. Postoperative pathological examination confirmed intralobar pulmonary sequestration with aspergillus infection. After 22 days of surgery, the level of serum CA19-9 and CA242 were significantly decreased and gradually decreased to normal. This is a rare case of pulmonary sequestration accompanied by aspergillus infection in which serum CA19-9 and CA242 are elevated; it's also the first report that pulmonary sequestration accompanied by aspergillus infection with sulfur particles formation. It is suggested that patients with pulmonary sequestration, especially those complicated with aspergillus infection, may be accompanied by elevated serum tumor markers CA19-9 and CA242, which should not be misdiagnosed as malignant tumors.
\end{abstract}

Keywords: Intralobar pulmonary sequestration; aspergillus infection; CA19-9; CA242; case report

Submitted Jun 29, 2020. Accepted for publication Oct 30, 2020.

doi: $10.21037 /$ tcr-20-2434

View this article at: http://dx.doi.org/10.21037/tcr-20-2434

\section{Introduction}

Pulmonary sequestration is a rare congenital developmental abnormality, which is characterized by the blood supply of a part of the lung tissue supplying by the systemic circulation. According to the relationship between isolated lung tissue and normal lung, pulmonary sequestration is divided into intralobar type and extralobar type. Intralobar pulmonary sequestration is more common than extralobar pulmonary sequestration, and the main site is the basal segment of the left lower lobe. Suspected patients can be diagnosed by pulmonary angiography, enhanced CT and CT threedimensional vascular reconstruction (1).

Many serum tumor markers, such as CA19-9, can be secreted by normal pancreatic ducts, biliary epithelium and gastric mucosal epithelium (2). The significant increase of serum CA19-9 often indicates malignant tumors of pancreas, biliary tract and gastrointestinal tract (3). However, it is non-specific, and the elevated level of CA19-9 can also be seen in many benign diseases, such as chronic pancreatitis in the digestive system, chronic hepatitis, primary biliary cirrhosis, gallstones, and primary 

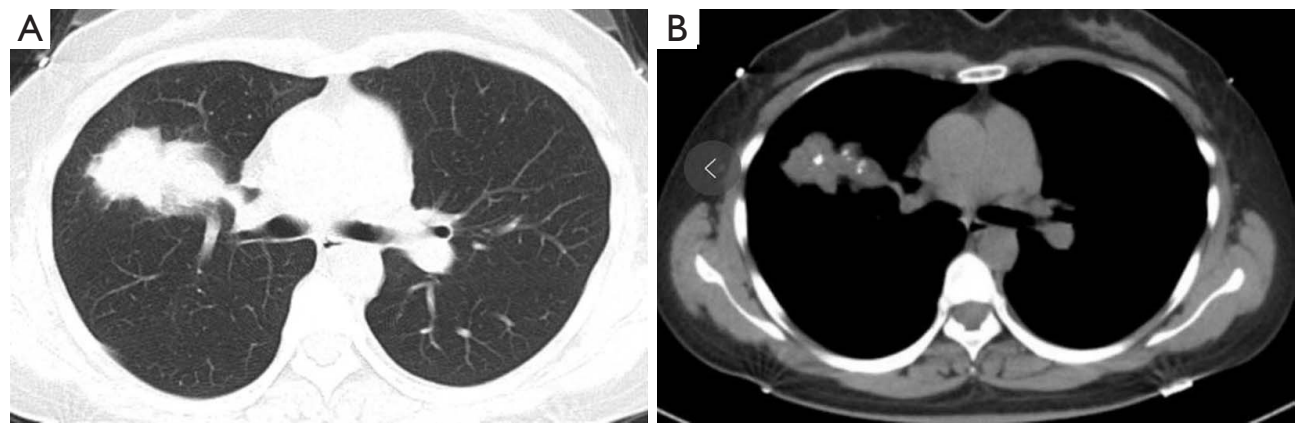

Figure 1 Chest CT image. (A) Chest CT lung window shows the soft tissue mass in the anterior segment of the right upper lobe, which is shallowly lobulated and burrs at the edges. (B) Chest CT longitudinal window shows the soft tissue mass in the anterior segment of the right upper lobe, with multiple calcifications.

sclerosis (4); idiopathic interstitial pneumonia of the respiratory system, collagen-related pulmonary fibrosis, diffuse panbronchiolitis, mediastinal bronchogenic cysts and mediastinal teratoma (5); and hydronephrosis, chronic glomerulonephritis, abnormal bone marrow hyperplasia syndrome, ovarian cysts, leiomyoma and other diseases (6). In 1988, Shiota et al. reported the increase of serum CA19-9 in a female patient with intralobar pulmonary sequestration for the first time (7). The mechanism of lung sequestration combined with elevated tumor markers such as CA19-9 in serum is not fully understood.

So far, intralobar pulmonary sequestration was caused by aspergillus infection are always uncommon. The cases of intralobar pneumonia with aspergillus infection accompanied by elevated serum CA19-9, especially elevated serum CA242, have never been reported. We present the following article in accordance with the CARE reporting checklist (8) (available at http://dx.doi. org/10.21037/tcr-20-2434).

\section{Case presentation}

A 36-year-old woman was found right lung occupying lesion in a routine physical examination on July 20, 2014 and was admitted to Peking Union Medical College Hospital in August 2014. A CT scan showed that there was a $5.6 \mathrm{~cm} \times 2.6 \mathrm{~cm}$ soft tissue masses in the anterior segment of the right upper lobe, which was shallowly lobulated, with burrs on the edges and multiple calcifications inside (Figure 1). Blood routine test display that white blood cell count was $6.28 \times 10^{9} / \mathrm{L}$, neutrophil percentage was $77.5 \%$, lymphocyte percentage was $18.5 \%$, hemoglobin was $133 \mathrm{~g} / \mathrm{L}$, and platelet count was $243 \times 10^{9} / \mathrm{L}$. Serum tumor marker test showed that CA19-9 increased significantly by $759.4 \mathrm{U} / \mathrm{mL}(0-34 \mathrm{U} / \mathrm{mL})$, CEA was $7.1 \mathrm{ng} / \mathrm{mL}$ (0-5 ng/mL), CA242>150 U/mL (0-34 U/mL), and no abnormalities were found in other CA series. The patient did not manifest any symptoms, such as cough, hemoptysis and so on. In addition, the patient's weight did not decrease significantly, and there was no smoking history.

Further, PET/CT examination was performed and showed that the radiopacity of the right middle lobe mass was unevenly increased (SUVavg $=2.6, \mathrm{SUVmax}=7.1$ ), and malignancy was not excluded. Bronchoscopy revealed a change in the opening of the right upper tip (double bronchial opening). Bronchoscopic alveolar lavage fluid examination showed that the acid-resistant mycobacteria, fungi and bacterial smear culture were negative, and no tumor cells were found in the pathology. The brush tissue culture was negative for tuberculosis, fungi and bacteria, and no tumor cells were found on the brush.

Comprehensive imaging examination and significantly elevated of CA19-9 in serum, it was strongly suspected to be a malignant tumor. Following the hospitalization of the patient on September 1, 2014, the thoracotomy was performed with patient consent and persistence on September 3. In the operation, it can be seen that the tumor is located in the anterior segment of the right upper lobe, crossing the horizontal fissure, invading the middle lobe of the right lung, and having double bronchial deformity in the upper lobe of the right lung. Right upper lobe, middle lobe resection, and lymph node dissection were performed during surgery.

The routine pathological investigation after surgery on September 11, 2014 showed the following characteristics. Two leaves of lung tissue were removed, interlobular 
fissures were found in the middle, lobes were incomplete, and the two leaves were connected; The total size of the two leaves was $9 \mathrm{~cm} \times 8 \mathrm{~cm} \times[1-3] \mathrm{cm}$, the surface of most of the capsule was smooth, and part had been cut open; open the lung along the bronchus, the double bronchial malformation can be seen in the upper lobe of the right lung, the bronchial mucosa is smooth, and a solid zone is visible in the lung tissue $0.5 \mathrm{~cm}$ away from the bronchial stump. The size of solid zone is $5 \mathrm{~cm} \times 2 \mathrm{~cm} \times 4.5 \mathrm{~cm}$, and the lesion is adjacent to the lung membrane and spans the leaf. The tissue section is solid and honeycomb, the diameter of the capsule is $0.1-0.2 \mathrm{~cm}$. Some Grayish-yellow sulfur particles can be seen in cysts, the solid area of the cyst was grayish-yellow, grayish brown, and nucleus. No clear lymph node-like tissue was found in the bronchial circumference, presenting the shape of book page, and no nodules were found in other lung tissues.

Histological observation by microscope demonstrate that the lung tissue in the lesion showed chronic pneumonia, while the bronchioles expanded multiply and became honeycomb. Part of the bronchial wall mucosal epithelium is incomplete and replaced by vascularized granulation tissue. There is interstitial fibrous tissue hyperplasia, as well as a large number of foam-like tissue cells and chronic inflammatory cell infiltration, accompanied by lymphoid follicle formation. Part of the lesion is adjacent to the interlobular rupture of the lung membrane, and the thick irregular thick-walled blood vessels are seen in the periphery, longitudinally across the interlobular rupture of the lung membrane, deep into the lesion area, suggesting abnormal blood supply in the lesion area, considered as intralobular pulmonary isolation (Figure $2 A$ ). Multiple fungal microfloras can be seen in the dilated lumen, and red stained protein-like exudation and inflammatory cells surrounding the colonies to form sulfur particles (Figure 2B); Special stain: fungal hexamine silver (+), PAS $(+)$. Fungal spores and hyphae can be seen by staining of Sodium hexamine silver, showing the diameter of the hyphae is about 5 microns with acute angles between branches and sections, which is considered to be aspergillus (Figure 2C).

The immunohistochemical results of CA19-9 showed that the bronchial mucosa epithelium, alveolar epithelium and intraluminal mucus staining were positive in the lesion (Figure 2D). The pathological diagnosis was intralobular pulmonary isolation with aspergillus infection and sulfur particle formation. The patient feels lucky for the final diagnosis (not the tumor). Except for the postoperative anti-infection treatment on September 22, 2014, the patient did not receive any other treatment after the operation until the serum markers and chest CT re-examination were performed on September 25, 2014. The re-examination result revealed that the patient's CA19-9, CA242 and CEA decreased significantly and no lump remained. On November 27, 2014, the second re-examination of serum markers showed that the levels of CA19-9, CA242, and CEA dropped to normal 2.5 months after the surgery (see Table 1). Later, the serum markers were re-examinated on April 1, 2015 and December 15, 2015. The results showed that the levels of CA19-9, CA242, and CEA remained normal, and the chest $\mathrm{CT}$ also showed no recurrence. The timeline of patient diagnosis and treatment have been shown in Figure 3.

All procedures performed in studies involving human participants were in accordance with the ethical standards of the institutional and/or national research committee(s) and with the Helsinki Declaration (as revised in 2013). Written informed consent was obtained from the patient.

\section{Discussion}

We identified 23 English articles in the PubMed database after searching with "Pulmonary sequestration" and "CA199". Among them, a total of 22 patients with lung isolation have elevated serum CA19-9 levels in 21 articles (see Table 2). However, no articles were identified in the WanFang and CNKI (China Knowledge Network databases) when we searched with the same keywords. Among the reported cases, there were 16 females and 6 males, and the number of females was significantly higher. The reported cases were predominantly adults, with an average age of 40 years (20-64 years), mostly were intralobular pulmonary isolation $(86 \%, 19 / 22)$. The mean level of CA19-9 in the patient's serum was $1,252.1 \mathrm{U} / \mathrm{mL}$ (73.8-4,200 U/mL). After surgically removing the isolated lung tissue, the serum CA19-9 level of the patient decreased to normal within 1 to 8 months, and no other malignant tumors were found after the operation.

The mechanism of pulmonary sequestration with elevated serum CA19-9 and other tumor markers is not completely clear. Many studies show that pulmonary sequestration with elevated CA19-9 is common in adults and intralobar type. CA19-9 was positive in bronchial mucosal epithelium and alveolar epithelium in the area of immunohistochemical lesion (7,9-13). It was speculated that pulmonary sequestration lesions, especially complicated 


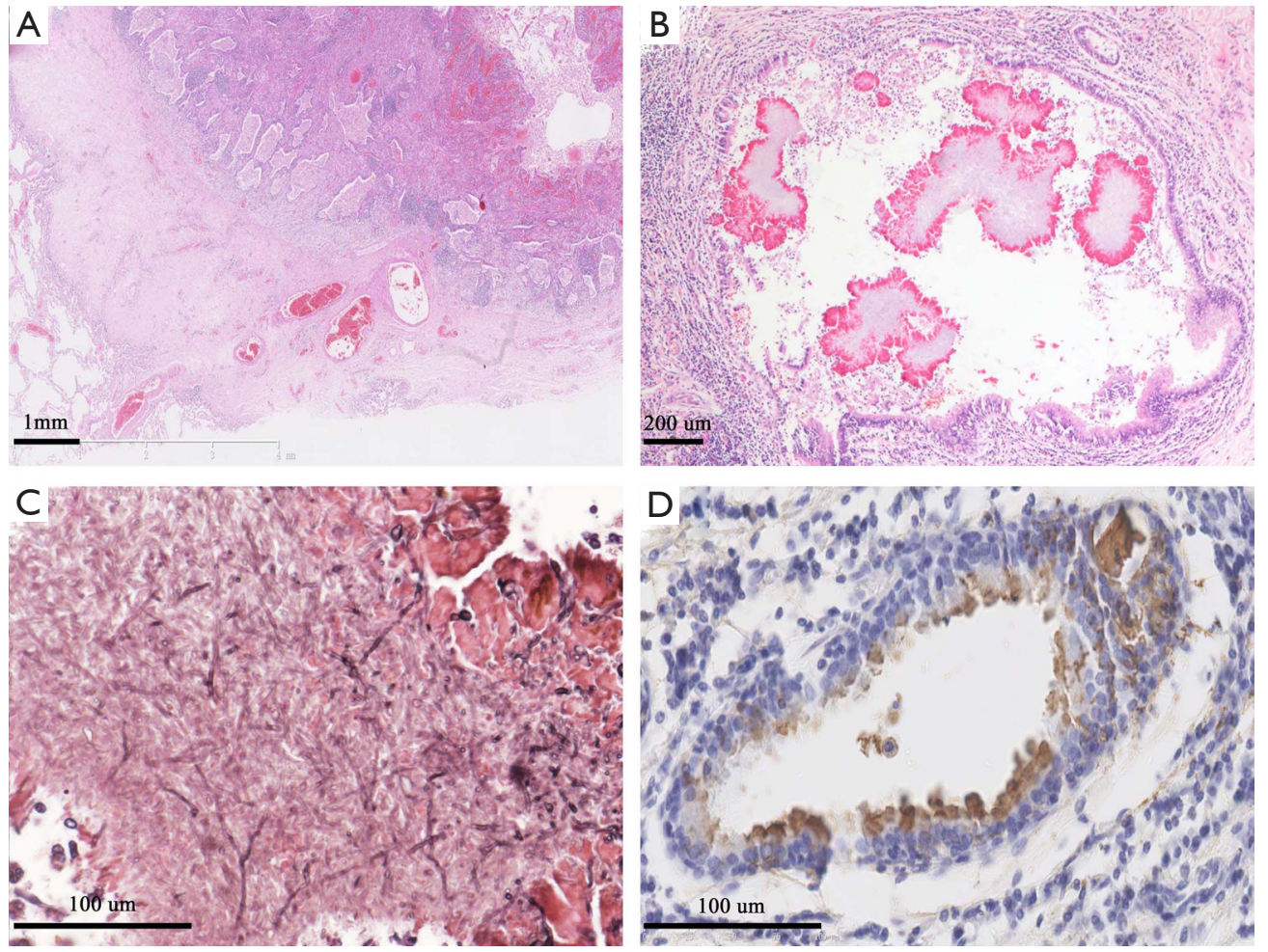

Figure 2 Pathology image of the lung. (A) Hematoxylin-eosin (HE) low magnification shows that the lesion area is adjacent to the interlobular rupture of the lung membrane, and the surrounding thick and irregular thick-walled blood vessels, spanning the interlobular rupture of the lung membrane, deep into the lesion area, suggesting abnormal blood supply in the lesion area (as indicated by the arrow), scale bar $=1 \mathrm{~mm}$. (B) Hematoxylin-eosin (HE) medium magnification shows that the multiple lumens of the fungal flora visible in the dilated lumen, and red stained protein-like exudation and inflammatory cells surround the colony to form sulfur particles, scale bar =200 $\mu$. (C) Hexamine silver staining shows fungal spores and hyphae. The diameter of hyphae was approximately 5 microns, acute angle branching and segmentation, considering the possibility of aspergillus (special staining, high magnification), scale bar =100 $\mu \mathrm{m}$. (D) High magnification immunohistochemical staining shows bronchial epithelial CA19-9(+), scale bar $=100 \mu \mathrm{m}$.

Table 1 The CA19-9, CA242, and CEA levels changes in serum before and after surgery in this patient

\begin{tabular}{lcccccc}
\hline Tumor markers & Before surgery & $\begin{array}{c}22 \text { days after } \\
\text { surgery }\end{array}$ & $\begin{array}{c}2 \text { months and 24 } \\
\text { days after surgery }\end{array}$ & $\begin{array}{c}7 \text { months after } \\
\text { surgery }\end{array}$ & $\begin{array}{c}15 \text { months after } \\
\text { surgery }\end{array}$ & Range \\
\hline CA19-9 $(\mathrm{U} / \mathrm{mL})$ & 759.4 & 140.9 & 28.3 & 20.1 & 19.3 & $0-34$ \\
CA242 $(\mathrm{U} / \mathrm{mL})$ & $>150$ & 62.3 & 18.8 & 18.3 & - & $0-20$ \\
CEA $(\mathrm{ng} / \mathrm{mL})$ & 7.14 & 1.7 & 1.81 & 1.45 & 1.26 & $0-5$ \\
\hline
\end{tabular}

with aspergillus or other pathogenic infection, promoted bronchial epithelial cells to synthesize and secrete CA199 (14), gathered in the dilated bronchial sac cavity, and entered into the blood through the damaged mucosa of the cyst wall (15).

Lung sequestration itself has no clinical symptoms, but when combined with pulmonary infection, infection-related respiratory symptoms can occur. In addition to common bacterial infections, there are also specific pathogens such as mycobacteria, nocardia and aspergillus $(16,17)$. There have been relatively few reports of aspergillus infections. So far, there are 31 cases, one of which is extralobular and the rest are intralobular. Sun et al. reported 7 cases of pulmonary isolation and pulmonary aspergillosis in 


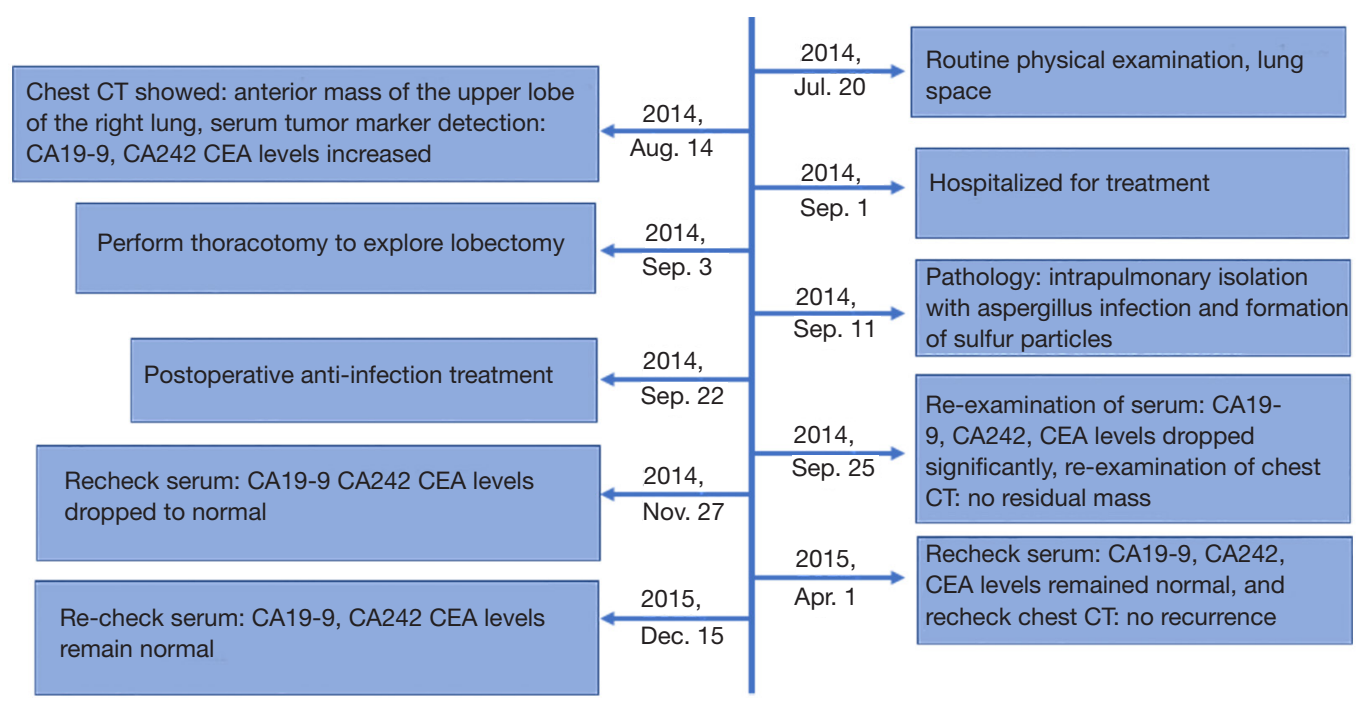

Figure 3 The timeline shows the entire diagnosis and treatment process of this case.

Peking Union Medical College Hospital, all of which were intralobular (18).

In this patient, multiple sulphur particles were seen in the bronchial cavity of the lung tissue expansion. Sulfur granules which are small yellow particles visible are round or elliptical. They are interwoven by mycelium, and the central part is basophilic, surrounded by eosinophilic, rounded rod-shaped hyphae. Sulfur granules are commonly found in actinomycetes, occasionally in nocardiosis, pigmented fungal disease, augmentation of bacteria, staphylococcus and aspergillosis. In the case of pulmonary sequestration with elevated CA19-9 (Table 2), 17\% (4/23) were associated with pulmonary aspergillosis. Intralobular lung isolation is often partially connected to the bronchus, which leads to the susceptibility to various pathogens, especially aspergillus (19-21). Most of the 7 patients with pulmonary isolation and pulmonary aspergillosis in Peking Union Medical College Hospital passed pathological examination, except one case was diagnosed by lung tissue culture, indicating that the clinical symptoms of the disease were concealed.

This article reports that a patient with a local solid mass in the upper lobe of the right lung was found by physical examination, accompanied by a significant increase of serum CA19-9. It was suspected of malignant tumor, and the patient was eager for operation without angiography and CTPA examination, and pulmonary sequestration could not be diagnosed before operation. Postoperative pathology confirmed intralobar pulmonary sequestration with aspergillosis infection. Pulmonary sequestration occurred in the upper lobe of the right lung, which occurred atypically. The serum CA19-9 decreased to normal level after surgical resection and isolation of the lung, suggesting that the increase of serum CA19-9 was caused by pulmonary sequestration, and aspergillus infection promoted the synthesis and secretion of CA19-9 in bronchial epithelial cells.

According to reports in the literature, in the serum of patients with pulmonary isolation, in addition to the elevated levels of CA19-9, levels of factors such as CA125, CEA, and CA50 are also elevated (22-26). The serum levels of CA242 and CEA were also significantly elevated in this patient, which is the first case of elevated serum CA242 in patients with pulmonary isolation. The serum levels of CA19-9, CA242, and CEA in patients with surgically removed lungs gradually decreased to normal, and no increase has been seen so far.

It has been reported that in addition to the increase of serum CA19-9, the serum levels of CA125, CEA and CA50 in patients with pulmonary sequestration can also be increased at the same time (21-25). The levels of serum CA242 >150 U/mL (0 20 U/mL) and CEA $7.14 \mathrm{ng} / \mathrm{mL}$ $(0-5 \mathrm{ng} / \mathrm{mL})$ were also significantly increased in this patient. After surgical resection and isolation of lung, the serum levels of CA19-9, CA242 and CEA gradually decreased to normal, and did not increase after follow-up.

This is a rare case of pulmonary sequestration accompanied by aspergillus infection in which serum 
Table 2 Summary of literature on pulmonary isolation with elevated serum CA19-9

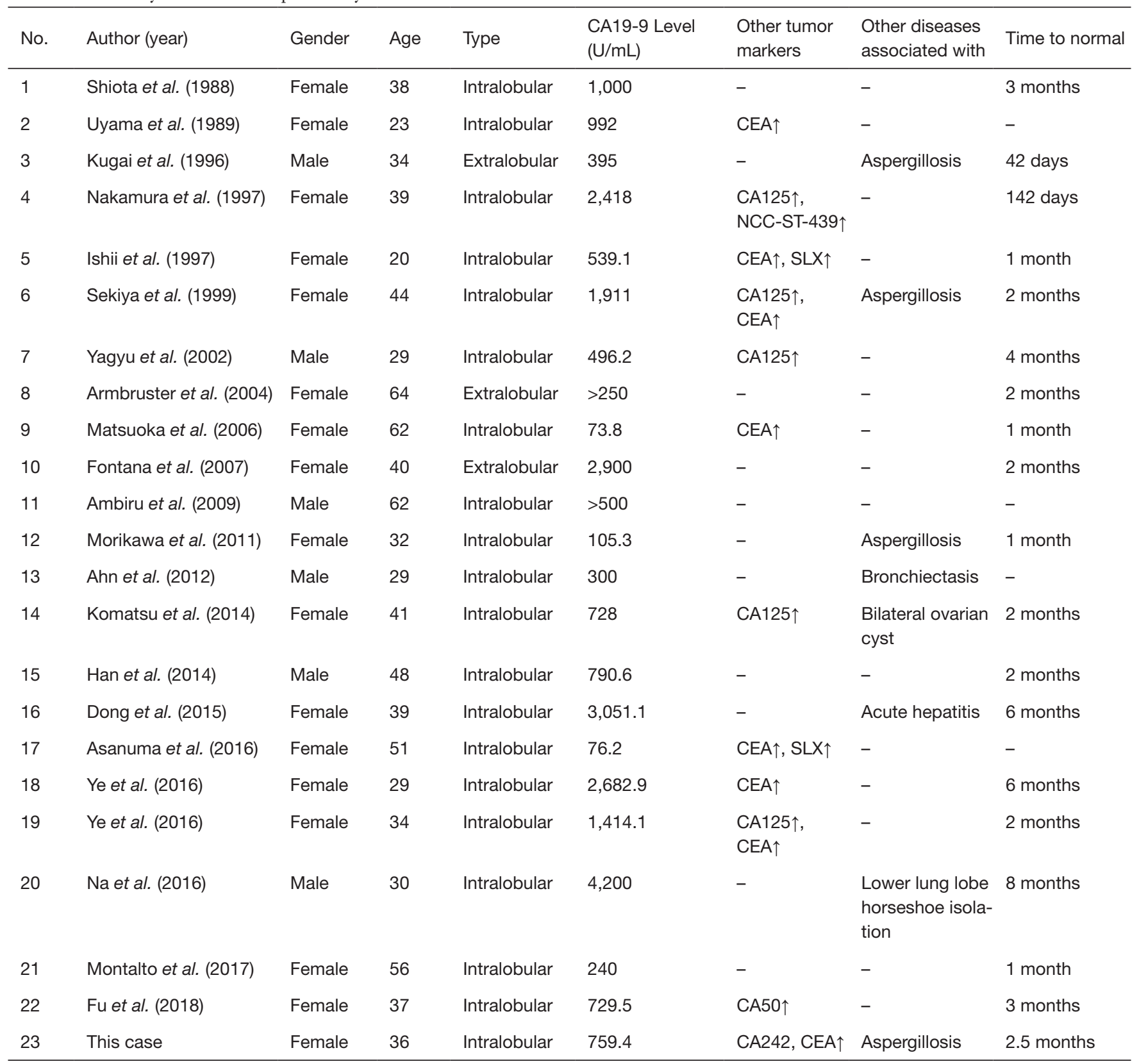

CA19-9 and CA242 are elevated; it's also the first report that pulmonary sequestration accompanied by aspergillus infection with elevated serum CA242 and formation of sulfur particles. Since this article is a case report, it also has the following limitations: first of all, the research in this article needs more cases to be validated. In addition, why are serum markers elevated in some patients with lung isolation? Its mechanism remains to be further studied.
Finally, elevated serum markers in patients with pulmonary isolation often are accompanied by aspergillus infection, and the relationship between the two remains to be further studied.

In summary, pulmonary sequestration patients, especially with aspergillus infection can be accompanied by elevated serum tumor markers, the most common is CA19-9, as well as CEA and CA125. Care should be taken not to diagnose 
this situation as malignancy.

\section{Acknowledgments}

Funding: None.

\section{Footnote}

Reporting Checklist: The authors have completed the CARE reporting checklist. Available at http://dx.doi.org/10.21037/ tcr-20-2434

Conflicts of Interest: All authors have completed the ICMJE uniform disclosure form (available at http://dx.doi. org/10.21037/tcr-20-2434). The authors have no conflicts of interest to declare.

Ethical Statement: The authors are accountable for all aspects of the work in ensuring that questions related to the accuracy or integrity of any part of the work are appropriately investigated and resolved. All procedures performed in studies involving human participants were in accordance with the ethical standards of the institutional and/or national research committee(s) and with the Helsinki Declaration (as revised in 2013). Written informed consent was obtained from the patient.

Open Access Statement: This is an Open Access article distributed in accordance with the Creative Commons Attribution-NonCommercial-NoDerivs 4.0 International License (CC BY-NC-ND 4.0), which permits the noncommercial replication and distribution of the article with the strict proviso that no changes or edits are made and the original work is properly cited (including links to both the formal publication through the relevant DOI and the license). See: https://creativecommons.org/licenses/by-nc-nd/4.0/.

\section{References}

1. Pryce DM. Lower accessory pulmonary artery with intralobar sequestration of lung; a report of seven cases. J Pathol Bacteriol 1946;58:457-67.

2. Kodama T, Satoh H, Ishikawa H, et al. Serum levels of CA19-9 in patients with nonmalignant respiratory diseases. J Clin Lab Anal 2007;21:103-6.

3. Steinberg $W$. The clinical utility of the CA 19-9 tumor associated antigen. Am J Gastroenterol 1990;85:350-5.

4. Gupta MK, Arciaga R, Bocci L, et al. Measurement of a monoclonal-antibody defined antigen (CA19-9) in the sera of patients with malignant and nonmalignant diseases. Comparison with carcinoembryonic antigen. Cancer 1985;56:277-83.

5. Uyama T, Monden Y, Sumitomo M, et al. CEA and CA 19-9 in benign pulmonary or mediastinal cystic lesions. J Surg Oncol 1989;41:103-8.

6. Ye X, Fu Y, Hu B, et al. Pulmonary sequestration associated with significant elevation of serum carbohydrate antigen19-9: report of two cases. Ann Transl Med 2016;4:373.

7. Shiota $Y$, Kitade M, Furuya K, et al. A case of intralobar pulmonary sequestration with high serum CA19-9 levels. Acta Med Okayama 1988;42:297-300.

8. Riley DS, Barber MS, Kienle GS, et al. CARE 2013 Explanations and Elaborations: Reporting Guidelines for Case Reports. J Clin Epidemiol 2017;89:218-35.

9. Han P, Luo Y, Tian D, Yan W, et al. Pulmonary sequestration presenting with left upper abdominal bloating and marked elevation of serum carbohydrate antigen 19-9: A case report. Oncol Lett 2014;7:1493-6.

10. Komatsu H, Mizuguchi S, Izumi N, et al. Pulmonary Sequestration Presenting Elevated CA19-9 and CA125 with Ovarian Cysts. Ann Thorac Cardiovasc Surg 2014;20 Suppl:686-8.

11. Ambiru $S$, Nakamura $S$, Fukasawa $M$, et al. Intralobar pulmonary sequestration associated with marked elevation of serum carbohydrate antigen 19-9. Ann Thorac Surg 2009;88:2010-1.

12. Fontana D, Della Beffa V, Fusca M, et al. Extralobar pulmonary sequestration showing high CA 19-19 levels. Minerva Chir 2007;62:39-42.

13. Yagyu H, Adachi H, Furukawa K, et al. Intralobar pulmonary sequestration presenting increased serum CA19-9 and CA125. Intern Med 2002;41:875-8.

14. Ahn YH, Song MJ, Park SH. Intralobar Pulmonary Sequestration Showing Increased Serum CA19-9. Tuberc Respir Dis (Seoul) 2012;72:507-10.

15. Matsuoka Y, Endo K, Kawamura Y, et al. Normal bronchial mucus contains high levels of cancer-associated antigens, CA125, CA19-9, and carcinoembryonic antigen. Cancer 1990;65:506-10.

16. Foucrier A, Woerther PL, Le Dorze M, et al. Pulmonary sequestration syndrome diagnosed from a Nocardia infection. Am J Respir Crit Care Med 2012;186:288.

17. Huang $X, X u X, Y u ~ C$, et al. Pulmonary sequestration with tuberculosis confined to the sequestrated lung. Ann Thorac Cardiovasc Surg 2012;18:51-5. 
18. Sun X, Xiao Y. A report of seven cases of pulmonary sequestration complicated by aspergillosis and literature review. Zhonghua Nei Ke Za Zhi 2014;53:873-5.

19. Morikawa H, Tanaka T, Hamaji M, et al. A case of aspergillosis associated with intralobar pulmonary sequestration. Asian Cardiovasc Thorac Ann 2011;19:66-8.

20. Sekiya $M$, Chiba $A$, Ienaga $H$, et al. Intralobar pulmonary sequestration presenting increased serum CEA, CA 19-9, and CA 125, and associated with asymptomatic pulmonary aspergillosis. Nihon Kokyuki Gakkai Zasshi 1999;37:433-7.

21. Kugai T, Kinjyo M. Extralobar sequestration presenting increased serum CA19-9 and associated with lung aspergillosis--an unusual case. Nihon Kyobu Geka Gakkai Zasshi 1996;44:565-9.

22. Fu S, Wang H. Pulmonary sequestration associated with a synchronous elevation of carbohydrate antigen 50 and 19-

Cite this article as: Ge L, Wang S, Liu H, Shi X, Shi J, Feng R. Intralobar pulmonary sequestration with aspergillus infection and elevated serum CA19-9 and CA242: a case report. Transl Cancer Res 2021;10(2):1169-1176. doi: 10.21037/tcr-20-2434
9: a case report. Ann Transl Med 2018;6:212.

23. Asanuma K, Ueda M, Kusano K, et al. Pulmonary Sequestration Associated with Increased Serum Tumor Markers;Report of a Case. Kyobu Geka 2016;69:800-3.

24. Ishii H, Mukae H, Ihiboshi H, et al. Pulmonary sequestration associated with high levels of tumor markers in serum. Nihon Kyobu Shikkan Gakkai Zasshi 1997;35:1029-33.

25. Nakamura H, Katsumi T, Nagata S, et al. A resected case of intralobar pulmonary sequestration with increased serum tumor markers, CA19-9, CA125 and NCC-ST-439. Nihon Kyobu Shikkan Gakkai Zasshi 1997;35:1425-9.

26. Uyama T, Monden Y, Harada K, et al. A case of intralobar pulmonary sequestration with calcification and elevated serum values of carcinoembryonic antigen and carbohydrate antigen 19-9. J Thorac Imaging 1989;4:74-6. 